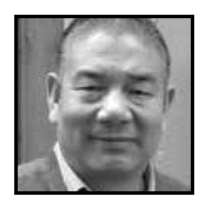

\title{
Teaching ICT to Pre-Service Teachers: Experiences and Reflections
}

\author{
Zuochen Zhang, University of Windsor
}

\begin{abstract}
Information and Communication Technologies (ICT) are increasingly used in education settings, and graduates from teacher education programs are expected to have adequate knowledge and skills to integrate ICT in their teaching. Inspired by some studies that report cases about pre-service teachers' ICT-related learning in different countries in Asia, this article presents, in case-study format, the experimentations carried out regarding the teaching of ICT as part of the curriculum to pre-service teachers in a teacher education program in Ontario, Canada. The aim is to share with instructors and researchers in teacher education institutions and programs what we can learn from our experiences, and how we can use these experiences to improve our practice.
\end{abstract}

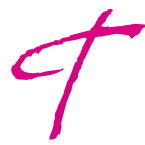

he important role Information and Communication Technologies (ICT) play in education has been increasingly recognized by educators of all levels. To help prepare future teachers who can make good use of ICT, teacher education institutions and programs are expected to not only "model the new pedagogies and tools for learning," but also "develop strategies and plans to enhance the teaching-learning process" (UNESCO, 2002, p. 13), the goal being to provide preservice teachers opportunities for experimentation with ICT before they can use them in classroom teaching (Albirini, 2006).

This article presents the experimentations carried out in a teacher education program in Ontario, Canada, regarding the teaching of ICT as part of the curriculum to pre-service teachers, with the aim to share with instructors and researchers in teacher 
education institutions and programs what we can learn from our experiences, and how in turn we can use these experiences to improve our practice.

In UNESCO Bangkok's (2013) publication, Case Studies on Integrating ICT Into Teacher Education Curriculum in Asia, the authors report cases such as a class or section of the pre-service teacher programs in Australia, China, South Korea, Philippines, Singapore, Thailand, and Vietnam. In their reports, the authors share challenges they experienced and strategies they employed by using collaborative learning, technology-enhanced learning, blended learning, and student-centered learning in their teaching practice, which can be valuable resources for curriculum design and policy reform in this field. Inspired by this publication, the author of this article, who has encountered many similar problems in his teaching, shares how efforts were made to apply constructivist paradigms by engaging pre-service teachers in collaborative learning in both face-toface classroom settings and web-based spaces. This article adapts the framework of the above-mentioned case studies that include: institutional context/background; context of the development of the ICT-related curriculum; outcomes: benefits and challenges; and conclusion and further implications.

\section{Institutional Context/Background}

\section{Introduction to the Faculty of Education at University of Windsor}

University of Windsor is one of the 12 universities in Ontario that offer consecutive teacher education programs. This program is 36 weeks long over one year, with 12 of those weeks devoted to teaching practice, which is organized in three or four blocks. This teacher education program, at least in recent years, has had an immensely diverse student population. These pre-service teachers are enrolled in divisions of Primary/ Junior (P/J), Junior/Intermediate $(\mathrm{J} / \mathrm{I})$, and Intermediate/Senior $(\mathrm{I} / \mathrm{S})$, and range in age from their 20s to their 50s. All of them possess a bachelor's degree and some have completed a Master's or higher degree, prior to enrolling in the pre-service program. The percentage of the pre-service teachers who completed degrees from countries other than Canada has been steadily increasing, and their presence in the pre-service program provides a reminder for the need of inclusion in an increasingly global society. Among the pre-service teachers, there is a wide variety in terms of their knowledge regarding creative and innovative uses of ICT (Bennett, Maton, \& Kervin, 2008). Those of a younger age appear to be more fluent in terms of ICT use (Martinovic \& Zhang, 2012; Zhang \& Martinovic, 2008). 


\section{Context of the Development of the ICT-Related Curriculum}

\section{ICT-Related Course/Curriculum}

Pre-service teachers enrolled in this program are required to take one ICT literacy course, which comprises a balance of theory and practice, besides other foundational courses and those that are in their specific subject areas ("teachables"). Some of these courses also involve use of ICT. The title of the course was "Instructional Technology (Computer Methods)" before 2011. Starting in the fall semester of 2011, it was changed to "Learning With Technologies." It is a general methods course offered to all the students in the Junior/Intermediate $(\mathrm{J} / \mathrm{I})$ and Intermediate/Senior $(\mathrm{I} / \mathrm{S})$ divisions. Since 2013 the course is offered as a required course to the Primary/Junior (P/J) division.

The course offers an introduction to influential theories related to the implementation of ICT in education and practice. In addition to this mandatory course, instructors of all subject areas within the pre-service program are expected to integrate ICT into their courses while modeling different uses of technologies. Besides introducing widely used hardware devices and software program packages, pre-service teachers are also exposed to:

the use of different kinds of accessible ICT, with the aim of helping them to understand how commonly accessible ICT, such as portable music players, inexpensive image or video recording devices, Open Source software packages, online synchronous and asynchronous communication tools (e.g., social networking software, mobile phone), can be used for teaching and learning purposes, and how these usages can help address equity issues in different schools. (Zhang, Tousignant, \& Xu, 2012, p. 7)

\section{Development Process}

The author of this article started teaching the ICT literacy course in the teacher education program in 2006, and a number of research projects on the course/curriculum have been carried out in order to develop an ICT-related course that provides preservice teachers with the best possible learning experience for their ICT knowledge and skills development.

A blended model that has both face-to-face and online learning was employed for the course delivery. During the first few years, the course was offered to J/I division as a full-year course, and a one-semester course to I/S division, which means $\mathrm{J} / \mathrm{I}$ students took the course for one hour each week for two semesters. In comparison, the I/S 
students took it for two hours each week for one semester. This course was not offered as a required course to $\mathrm{P} / \mathrm{J}$ division until the 2011 academic year.

Based on findings of research projects and student feedback from 2006 to 2010, which indicated that I/S students needed more time to digest what they learned in the ICT course, and that $\mathrm{P} / \mathrm{J}$ students needed a course dedicated to ICT learning, the course was changed to a full-year course for I/S students in 2011. In the same year, the course was offered as a test run to $\mathrm{P} / \mathrm{J}$ students as a two-semester course for one year. As a result of the curriculum reform in the program, starting in the fall semester of 2013 , the course Learning with Technologies has been offered to $\mathrm{P} / \mathrm{J}$ students as a required course.

\section{Infrastructure for ICT Teaching and Learning}

All the classrooms, except for the computer classroom in the faculty, are equipped with a multimedia cart that has a data projector, a DVD/VHS combo, speakers, and a Mac mini computer with both Mac and Windows operating systems installed. A few classrooms have a document camera on the teacher's desk. Most classrooms also have a SmartBoard installed.

Three years ago, a Learning Resource Center was created with funding from student fees. The center is equipped with photocopiers, printers, a SmartBoard, a green wall for video shooting, a die cutting machine, and four computers. A small soundproof room inside the center is dedicated for audio and video editing. In this room there are two Mac computers with special software (e.g., Final Cut Pro, Adobe Premier Pro CC) installed, and high quality microphones and speakers. All pre-service teachers have entry to the center with access privilege programmed on their student card.

The largest class in the teacher education program is usually 40 students. Because of the limited physical space in the computer classroom, there are only 35 Mac computers in this room, and one of them is on the teacher's desk. These computers have three operating systems (Mac OS, Windows 8, and Linux) installed, so that preservice teachers can be exposed to different operating systems that are used in schools. The application software packages installed are mostly those licensed by OSAPAC (Ontario Software Acquisition Program Advisory Committee). In 2008, when the computer classroom was renovated, 25 computers were put in the classroom, and two keyboards were connected to each computer, with the hope that this configuration would give students more opportunities to collaborate. It turned out that the extra keyboard was seldom used, so they were removed after one semester. 


\section{BYOD (Bring Your Own Device)}

With the increasing affordability of laptop computers and other handheld devices, such as iPads and other tablets, more and more pre-service teachers are bringing their own device into the classroom. In fact, many of them prefer to use their own device unless they have to use the software only available on the classroom computers. At first they were allowed to use their own device, but later on, as wifi became more reliable and more pre-service teachers owned mobile devices, they were encouraged to bring their own and use them in the ICT class.

Learning With Technologies is a course that is dedicated to ICT literacy development for pre-service teachers in the teacher education program, and each division has its specific focus. For example, I/S students are required to have two teachables (subject areas), J/I students have one teachable, and P/J students are "generalists" who do not have specific teachables, so the course is adjusted to meet the needs of each division. Each academic year the course content is revised with updated reading materials and course assignments. The course outline for I/S division for the academic year of 20132014 is included in this article as a sample.

\section{Course Topics and Instructional Strategies}

This is a course on ICT literacy, rather than a computer skills course, as many students would assume before entering the course. The course is designed to use a learnercentered approach so the instructor only gives a few lectures. Most class activities are done by pre-service teachers with the instructor as a guide. During the course preservice teachers are required to choose one of the required readings, and in a group of five to eight people (depending on number of students in a class), they will do an in-class presentation which has three components including a: brief summary, critique on the reading, and class discussion on the reading. For the critique, students are expected to not only make insightful comments on the reading itself, but also those related to their own experiences and observations regarding what is discussed in the reading. In the class discussion, students are expected to raise thought-provoking questions, and by using their facilitating strategies, get all class members involved in the learning process.

Tech Workshops are designed for pre-service teachers to sign up for a workshop on their interested topic, and run a 15-20 minute workshop individually or in a group of up to three people. Requirements for a tech workshop include accessibility, availability, practicability, and hands-on practice. Students are encouraged to run a workshop on something they learn by themselves after entering the course, so as to not only learn ICT, but also practice how to teach their knowledge and skills to others. There were a 
wide variety of topics pre-service teachers did their Tech Workshop on in the past few years. There was a group of three who had very limited knowledge in ICT and they were struggling to find a topic for their workshop. With suggestions from the instructor, they taught themselves how to use Windows Movie Maker, and then ran a workshop for the rest of the class demonstrating how to use the software. In addition to software programs, hardware use is also a topic for workshops. It was brought to the author's attention a few years ago that many pre-service teachers who owned a Mac laptop computer did not know that they needed a special adaptor to connect their computer to a data projector. So, a workshop is usually arranged for them to learn how to properly connect a laptop computer to a data projector, and what type of adaptor they should buy for their computer. Some Windows laptops have an HDMI port but no VGA port, like most computers do, so the owners of such computers should know what to prepare if they want to use their own device during their practicum. Pre-service teachers find a lot of video clips on YouTube that they would like to integrate in their classroom teaching, but many schools have certain websites blocked, including YouTube. As such, there are workshops to teach them how to use programs such as KeepVid or MacX YouTube Downloader to save the video clips on their own computer (they are cautioned not to infringe on copyrights) to play them offline.

Online learning activities are designed for students to make use of the online learning environment on the learning management system (LMS); and also for the instructor and students to communicate about the course. There are five required online discussions throughout the course. The first required online discussion asks students to make a posting about their experiences and perceived competency of ICT, and then express what they expect to learn in this course. This serves as a way for a needs assessment so the instructor can adjust the delivery pace and course content based on students' background and expectations. Postings in the first required online discussion show a big variety of pre-service teachers' ICT competency. For instance, there was one posting showing limited ICT competence:

In my past, I have used the ICTs Microsoft Word, Microsoft Excel and Microsoft PowerPoint, which I have primarily used for my education. In this class I am looking forward to learning how to use a SmartBoard since its popularity in classrooms is rapidly increasing, and also iMovie because I believe using this in my classroom would help motivate my students to learn.

While another from a more experienced ICT user stating that: 
I believe I have a fair amount of knowledge about ICT and have used a few forms. I am comfortable working on a Mac or a PC in any of these programs. I am fluent with Microsoft Office (PowerPoint, Word, Excel), Adobe Photoshop, iMovie, iPhoto, Garage Band, to name a few. I am really looking forward to learning how to use a SmartBoard and integrating technology such as iPads into my classroom.

Topics such as SmartBoard are what pre-service teachers expect to learn, regardless of their previous ICT competence, so after introducing them in class, a Graduate Assistant is assigned to run workshops on those topics in the Learning Resource Center for those who need extra sessions.

During each practicum, pre-service teachers are asked to observe what types of ICT are available and how they are used in their placement school. At the end of the practicum, all students will make a posting about their observation and their reflections of the availability and use of ICT in their placement school. From the postings, it is found that many schools have different types of ICT that are used to various degrees depending on the subject and associate teacher (in-service teacher who mentors the pre-service teacher during the practicum). The following posting provides information on what is done in schools that may be worth considering in the teacher education program:

My Associate and many others also use two forms of communication with students and parents that are quite different. The first is a Weebly website that is created by each teacher. They then create a page on that site for each of their classes and any extra-curriculars or events they are part of. Each class page contains grades (coded by student number), lesson notes, handouts and any extra materials of interest. The second system is a text-messaging service called Remind 101. Teachers set up an account for each class or period and are able to send out messages to their students and their parents, whomever signs up for the service. The important thing to note is that there is no exchange of information, as everyone's numbers are private and alias names are allowed (especially for the parents of students). This service is used to remind students to study for tests, finish their homework, and about upcoming events.

Towards the end of the course, pre-service teachers are asked to share in the online forum what they believe they have learned in this course, and recommend improvements for future students. The following postings represent suggestions from many pre-service teachers, indicating they do not really recognize the importance of readings, and they would like to have more clarity about the requirements for assignments: 
I would improve tech class by adding more workshops and having less discussion on readings. I didn't find the readings to be of any use in my placements. I really enjoyed the tech workshops and they are things I can use in my classroom. The more I know, the better equipped I am to use technology in my classroom.

My suggestions for this course would be to have more elaborate[d] explanations of the assignments as well as exemplars and rubrics to accompany them. This would eliminate any doubt for me as a student about what is expected of me.

For the final assignment, students are asked to work in groups of two to five to create a project in a digital format, such as a movie, website, interactive presentation, computer program, or a combination of two or more of the aforementioned to be used as a resource website, tutorial, or presentation for a mini research project. Software programs such as Adobe Dreamweaver and iMovie are taught in class, and presentation programs such as Microsoft PowerPoint, Keynote, and Prezi are commonly chosen topics for Tech Workshops, so pre-service teachers can choose one or more programs as a tool for their final project. A group of pre-service teachers with biology as their teachable made a PowerPoint presentation introducing parts of a human body, where a mouse click on a part (e.g., heart) would bring up an animation, video clip, or an explanation of its function. A game in the format of Jeopardy followed the introduction as a quiz to enhance what was learned on the previous slide. Another group carried out a small research project on children's understanding of Internet safety. With permission of the parents, the group videotaped two children aged six and 10 while asking them questions on what they knew about Internet use. They then edited the footage using iMovie to make a short movie that shows how much these children really knew. Many groups made multimedia resource websites for French learning, history of a certain country, and introduction to a number of musical instruments. Pre-service teachers of different teachables group together to take advantage of each member's expertise, and collaboratively some take care of the content while others are responsible for the technical aspects of the project.

Class assignments involve both individual and group work. For group work, students are discouraged to have the same group members for different assignments so that they have opportunities to collaborate with different people, and the development of their collaborative skills can be optimized.

As it is widely agreed upon that an ICT literacy course should not only address knowledge and skills of the implementation of technologies, but also topics closely related to social and economic issues (for example, the digital divide), it is necessary 
for such a course to raise awareness of these issues among pre-service teachers and expose them to possible solutions to such problems (Zhang, Tousignant, \& Xu, 2012, p. 3). Widely accessible equipment and programs such as SmoothBoard, Open Source, and free software are introduced in class, and students are encouraged to explore them. The following table presents what have been most frequently used in this course during the past few years.

\section{Table 1}

Hardware, Software, and Websites Used in the ICT Literacy Course

\begin{tabular}{|l|l|l|}
\hline HARDWARE & SOFTWARE & WEBSITES \\
Camera & Audacity & Bitstrips \\
(Mac and PC) & Bitstrips & Blogging platforms \\
iPad & Dreamweaver & Facebook \\
iPod & GarageBand & Gizmos \\
Laptop & Geometers sketch pad & Google \\
Lego robotics & iMovie & Google Docs \\
Microphone & iPhoto & Google Panorama \\
Monitors & iWeb & Polleverywhere.com \\
Printer & Keynote & Prezi \\
Scanner & Maple & SeaMonkey \\
SMART Board & Microsoft Excel & Skype \\
Speakers & Microsoft PowerPoint & SMART Exchange \\
USB memory sticks & Microsoft Word & Twitter \\
Video camera & One Note & Webmail \\
\hline & Pages & Webquests \\
Photoshop & Weebly \\
\hline & Sketchbook Pro & Wikipedia \\
\hline
\end{tabular}


Among the items listed in Table 1, some were more frequently used than others. For example, SMART Board was used for most interactive class activities, including in-class presentations and workshops. PowerPoint and/or Prezi, often with YouTube videos embedded, were used by pre-service teachers almost as the default program in their presentations. Pre-service teachers who were familiar with Mac computers would choose iMovie to make video clips, while those who felt more comfortable using Windows operating systems, or who preferred to use more accessible software, would use Windows Movie Maker for this purpose. Dreamweaver was part of the OSAPAC licensed package, which is installed on all the computers in the computer classroom and Learning Resource Center, and available for all the schools in Ontario. In addition, SeaMonkey, an alternative program for webpage development, was also introduced in the ICT course and many pre-service teachers used it for their projects because of its easy access. Skype was used a number of times during the past few years when a guest speaker from a different location was invited. On a few occasions, it was also used to connect to pre-service teachers who could not come to class due to health reasons.

\section{Course Assessment}

Class participation includes attendance and active participation in all class activities. Pre-service teachers are required to attend all the face-to-face meetings and are encouraged to actively participate in discussions. Due to time limitation, some discussions are extended in the online forum, so participation is also expected there.

Tech workshops are assessed according to the requirements explained in class and also posted on the course website. Additional factors used for the assessment include appropriateness of the pace and interactions between students who run the workshop and the audience. Time management and coordination among team members (if it is done by a team) are also considered.

Time allotment for the discussion on the reading activity is 15 minutes (summary: three minutes; critique: six minutes; class discussion: six minutes). Higher order learning is emphasized for the pre-service teachers, so more attention is paid to insightful critique and thought-provoking class discussion than the descriptive summary of the reading material. Presentation skills, coordination among group members, and time management are also used as factors for the assessment.

Required online discussions are assignments for individuals and they are designed as tools for carrying out needs assessment, sharing observations and reflections for each practicum, and conducting online action research to improve the course (Zhang, 2010). 
The final project is designed for pre-service teachers to complete in groups of two to five. They are asked to form their own groups and submit the final project on a computer server that is dedicated for the course. As the server is connected to the Internet, it is made clear for the pre-service teachers to keep in mind issues related to intellectual property, especially when they use resources from the Internet. When the final project is submitted, all group members are required to email the instructor their self- and peer evaluation, indicating what mark they believe each group member deserves for the project.

\section{Outcomes: Benefits and Challenges}

\section{Benefits}

Based on pre-service teachers' reflections and research projects conducted by the author and his colleagues in the past few years, the ICT literacy course provides students with theoretical and practical knowledge related to the use of ICT for teaching and learning. Through the course, pre-service teachers understand the importance of technological pedagogical content knowledge (TPACK) (Mishra \& Koehler, 2006) for teachers in ICT-rich learning environments. The course is designed to develop preservice teachers' ICT literacy; that is, besides learning pedagogical values of ICT and how to employ them for teaching and learning, they also have their critical thinking skills, lifelong learning skills, and collaborative learning/working skills developed. The following posting represents the opinion of those who had limited ICT knowledge and skills and found this course beneficial:

Before this class I had very limited ICT literacy. I did not like using technology simply because I feared it not working or something going wrong. This course has taught me a lot about ICT and I believe the tech workshops were most valuable. Every one of the Tech workshops can be used in my future career as a teacher. This course was not what I expected, but in the end it did teach me a lot and I am glad I took the course.

This course has definitely changed my perceptions and attitudes towards the integration of ICT into my classroom. I now believe technology is a great tool to use. Students enjoy the use of technology in the classroom and technology helps students learn the material better. It also is more engaging for students and catches their attention right from the start. Personally, I used videos when teaching my history class and it helped my students understand the material and stay on task. 
There are also indications that during their teaching practica, while learning from their associate teachers, some pre-service teachers helped their associate teachers to learn ICT, or positively influence their attitudes towards ICT integrated teaching. For instance, one pre-service teacher shares their experience that,

Like many veteran teachers, my associate does not use much ICT in her teaching even if they are available. After seeing me using different types of ICT, she told me she found them helpful and would try using them in her classroom teaching.

\section{Challenges and Solutions}

Like what was reported in Lim (2013), challenges for this ICT literacy course come from the fact that pre-service teachers have a diversity of ICT competencies before entering the teacher education program. Moreover, even if they have previous knowledge and skills in terms of ICT for daily life use, they most likely lack pedagogical knowledge and strategies to use ICT for teaching and learning. Those with more ICT competence would prefer to have less class time spent on basic knowledge and skills of commonly used ICT, while those who have limited background in ICT would be overwhelmed if too many new terms are introduced in one class-and it is no easy task to keep a balance in terms of pace and content.

Having group assignments is one of the ways to help pre-service teachers with different ICT competencies to work together and learn from each other. The author of this article and his colleagues conducted research from different aspects of the course and made recommendations to offer the ICT literacy course with different levels of difficulty. So far this kind of accommodation has not been possible due to the complexity of scheduling. Students are encouraged to take advantage of relevant workshops offered by the university library and Center for Teaching and Learning, a unit that is responsible for faculty and staff professional development, and that offers some online tutorials for those who need extra resources. Having a tech coach at the Learning Resource Center is found to be quite helpful, especially for those with low competence in ICT.

Providing enough information about the course requirements and assignments is more often than not a challenge. Besides what is stated in the course syllabus, verbal explanation is given during class meetings, and additional explanations are posted on the course website in the format of $Q$ \& $A$, but from time to time questions still arise about requirements for assignments. A quiz on this information may be necessary to help pre-service teachers get a good knowledge in this regard at an early stage. 
In order to best meet the learning needs of all pre-service teachers in the program, the ICT literacy course "has been undergoing continuous development and improvement" (Nguyen, 2013, p. 94) so that the course is made "current, relevant and pedagogically sound" (Wong \& Divaharan, 2013, p. 70). Since 2006, in order to prepare pre-service teachers with adequate ICT literacy, a number of research projects have been conducted (e.g., Martinovic \& Zhang, 2012; Zhang, 2010; Zhang \& Martinovic, 2008; Zhang \& Martinovic, 2014; Zhang \& Nielsen, 2014; Zhang, Tousignant \& Xu, 2012) so as to provide a valuable learning experience not only through the ICT literacy course, but also through other courses in the program. Instructors of all the courses in the program are expected to model the use of ICT in their teaching. However, one of the challenges in this regard is that instructors in the program have various perspectives of and attitudes towards the role of ICT for teaching and learning (Zhang \& Nielsen, 2014). As such time and effort are needed before an integrated model of ICT teaching and modeling is implemented in the teacher education program.

\section{Conclusion and Further Implications}

The course Learning With Technologies is a general methods course designed for pre-service teachers to gain basic knowledge and skills on how to use ICT for teaching and learning. As an ICT literacy course, it is not only for pre-service teachers to learn how to use computer hardware and software, but also "to gain a sense of technology integration and of pedagogical thinking with ICT" (Kim, 2013, p. 39).

It takes more than a course in a teacher education program for pre-service teachers to get well prepared as future teachers who can effectively integrate ICT into their course design and classroom teaching. A learning environment needs to be created program-wide so that pre-service teachers can be exposed to various kinds of ICT so by the end of the program, they will have a good mastery of technological and pedagogical knowledge and skills of ICT integration in both subject-specific areas and the curriculum level. It is also important to have more collaboration among different units of the institution to make it possible for pre-service teachers to have opportunities to learn and enhance their ICT knowledge and skills campus-wide. Ongoing communication with school boards and in-service teachers should be carried out, so that what preservice teachers learn from the teacher education program is properly aligned with the real teaching practice in schools. 
The importance of research, especially action research, on the courses and curriculum cannot be overstated. The field of ICT is rapidly changing and student characteristics keep changing as well. Therefore, curriculum designers and instructors of teacher education programs need to continuously conduct research so they can keep themselves well informed for further improvements of their future practice.

\section{References}

Albirini, A. (2006). Teachers' attitudes toward information and communication technologies: The case of Syrian EFL teachers. Computers \& Education, 47, 373-398.

Bennett, S., Maton, K., \& Kervin, L. (2008). The "digital natives" debate: A critical review of the evidence. British Journal of Educational Technology, 39(5), 775-786.

Kim, H. (2013). A project-based course for learning to teach with ICT: A case of pre-service teacher education (Republic of Korea). In UNESCO Bangkok (Ed.), Case studies on integrating ICT into teacher education curriculum in Asia (pp. 29-39). Bangkok: UNESCO, Asia and Pacific Regional Bureau for Education.

Lim, C.P. (2013). Building pre-service teachers' ICT in education competencies at Edith Cowan University (Australia). In UNESCO Bangkok (Ed.), Case studies on integrating ICT into teacher education curriculum in Asia (pp. 1-20). Bangkok: UNESCO, Asia and Pacific Regional Bureau for Education.

Martinovic, D., \& Zhang, Z. (2012). Situating ICT in the teacher education program: Overcoming challenges, fulfilling expectations. Teaching and Teacher Education, 28(3), 461-469.

Mishra, P., \& Koehler, M. (2006). Technological pedagogical content knowledge: A framework for teacher knowledge. Teachers College Record, 108(6), 1017-1054.

Nguyen, V.H. (2013). Learning to teach with ICT: A project-based course for pre-service teachers of biology at Hanoi National University of Education (Viet Nam). In UNESCO Bangkok (Ed.), Case studies on integrating ICT into teacher education curriculum in Asia (pp.
81-94). Bangkok: UNESCO, Asia and Pacific Regional Bureau for Education.

UNESCO. (2002). Information and communication technologies in teacher education: A planning guide. Paris: UNESCO, Division of Higher Education.

UNESCO Bangkok. (2013). Case studies on integrating ICT into teacher education curriculum in Asia. Bangkok: UNESCO, Asia and Pacific Regional Bureau for Education.

Wong, P., \& Divaharan, S. (2013). ICT for meaningful learning (Singapore). In UNESCO Bangkok (Ed.), Case studies on integrating ICT into teacher education curriculum in Asia (pp. 55-70). Bangkok: UNESCO, Asia and Pacific Regional Bureau for Education.

Zhang, Z. (2010). Using online action research to improve a teacher education course. Ontario Action Researcher, 11(1). Retrieved from: http://oar.nipissingu.ca/PDFS/V1112.pdf

Zhang, Z., \& Martinovic, D. (2008). ICT in teacher education: Examining needs, expectations and attitudes. Canadian Journal of Learning and Technology, 34(2), 149-166.

Zhang, Z., \& Martinovic, D. (2014). Teacher candidates' implementation of information and communication technologies: Perceptions of school teachers. Manuscript in preparation.

Zhang, Z., \& Nielsen, W. (2014). ICT use in teacher education programs: Perspectives of instructors. Manuscript in preparation.

Zhang, Z., Tousignant, W., \& Xu, S. (2012). Introducing accessible ICT to teacher candidates: A way to address equity issues. Journal of Literacy and Technology, 13(1), 2-18. 


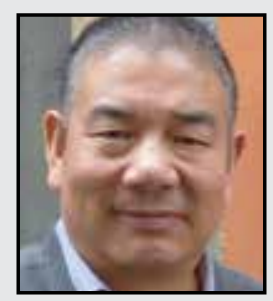

Zuochen Zhang is Associate Professor in the Faculty of Education at the University of Windsor, Canada. He has taught Learning With Technologies courses for the Teacher Education program; Information and Communication Technologies (ICT) for Teaching and Learning; and Educational Research to students in the Master of Education program. Dr. Zhang's research interests include ICT integration into school curriculum, e-learning, teacher education, Teaching English as a Second Language (TESL)/Teaching English as a Foreign Language (TEFL), and international education.

\section{LINK TO:}

http://www1.uwindsor.ca/education/10/dr-zuochen-zhang 